LISANUL ARAB 10(2)(2021)
(Terakreditasi Sinta 4)
http://journal.unnes.ac.id/sju/index.php/laa

\title{
MUBTADA' (TOPIC) DAN KHABAR (COMMENT) DALAM KITAB SAFINATUN NAJA KARYA SYEIKH SALIM BIN ABDULLAH BIN SAID BIN SUMAIR AL HADRAMIY (ANALISIS SINTAKSIS)
}

\author{
Anang Ramadlon ${ }^{\bowtie}$, Hasan Busri ${ }^{\bowtie}$, Zaim Elmubarok $\bowtie$ \\ Jurusan Bahasa Asing, Fakultas Bahasa dan Seni, Universitas Negeri Semarang, Indonesia
}

\begin{tabular}{l}
\hline Info Artikel \\
\hline Sejarah Artikel: \\
Diterima Oktober 2021 \\
Disetujui November 2021 \\
Dipublikasikan \\
November 2021 \\
\hline
\end{tabular}

Keywords:

Sintaksis; Mubtada' (topic) dan Khabar (comment); Kitab Safinatun Naja.

\begin{abstract}
Abstrak
Mubtada' merupakan isim marfu' yang bebas dari amil lafadz. Sedangkan khabar (comment) merupakan isim marfu' guna melengkapi makna mubtada'(topic). Penelitian ini merupakan penelitian kualitatif dengan desain penelitian library research. Instrumen yang digunakan dalam penelitian ini berupa kartu data dan lembar rekapitulasi. Teknik pengumpulan data menggunakan teknik dokumentsi. Teknik analisis data menggunakan metode distribusional teknik bagi unsur langsung, dan teknik pemeriksaan keabsahan data menggunakan teknik uji kredibilitas meningkatkan ketekunan. Berdasarkan penelitian yang dilakukan oleh peneliti, peneliti menemukan 279 data berupa mubtada (topic) dan khabar (comment), karena banyaknya data yang hampir sama maka peneliti mengambil 89 data untuk dianalisis secara mendalam. Dari 89 mubtada'(topic) tersebut, 89 merupakan mubtada'(topic) sharih dan tidak ada satupun mubtada'(topic) muawwal. Berdasarkan ketentuan penggunaannya terdiri atas tidak ada satupun mubtada' (topic) yang wajib mahdzuf dan 3 boleh mahdzuf, 82 wajib muqaddam dan 2 boleh muqaddam, dan 1 wajib muakhkhar dan 1 boleh muakhkhar. Berdasarkan penanda gramatikalnya terdiri atas 75 mubtada' (topic) dengan penanda gramatikal dlammah, tidak ada satupun dengan penanda gramatikal alif, waw, dan nun, dan 14 mubtada' (topic) yang menempati fungsi mubtada' (topic) (machal rafa'). Dan dari 89 khabar (comment), 64 merupakan khabar (comment) mufrad dan 25 merupakan khabar (comment) ghairu mufad. Berdasarkan ketentuan penggunaannya terdiri atas tidak ada satupun khabar (comment) yang wajib dan boleh mahdzuf, 1 wajib dan boleh muqaddam, dan 85 wajib muakhkhar dan 2 boleh muakhkhar.
\end{abstract}

(C) 2021 Universitas Negeri Semarang

Mubtada 'isim marfu' which is free from amil lafadz. While khabar (comment) is an isim marfu' to complete the meaning of mubtada' (topic). This research is a qualitative research with library research research design. The instruments used in this study were data cards and recapitulation sheets. Data collection techniques using documentation techniques. The data analysis technique uses the distributional method for the direct element, and the data validity check technique uses the credibility test technique to increase persistence. Based on the research conducted by the researcher, the researcher found 279 data in the form of mubtada (topic) and khabar (comment), because the amount of data was almost the same, the researcher took 89 data for in-depth analysis. Of the 89 mubtada'(topic), 89 are mubtada'(topic) sharih and none of the mubtada'(topic) muawwal. Based on the terms of use, there are no mubtada '(topics) that are obligatory mahdzuf and 3 may be mahdzuf, 82 are obligatory muqaddam and 2 may be muqaddam, and 1 is obligatory muakhkhar and 1 may be muakhkhar. Based on the grammatical markers, it consists of 75 mubtada' (topic) with the grammatical marker dlammah, none with the grammatical marker alif, waw, and nun, and 14 mubtada' (topic) which occupies the function of mubtada' (topic) (machal rafa'). And of the 89 khabar (comments), 64 are mufrad khabar (comments) and 25 are ghairu mufad khabar (comments). Based on the terms of use, there is no khabar (comment) that is obligatory and can be mahdzuf, 1 is mandatory and can be muqaddam, and 85 is obligatory muakhkhar and 2 may be muakhkhar.

\begin{tabular}{ll}
\hline Alamat korespondensi: & P- ISSN 2252-6269 \\
Gedung B9 Lantai 2 FBS Unnes Kampus Sekaran, Gunungpati, Semarang, 50229 & E- ISSN 2721-4222 \\
E-mail: anang.rama99@gmail.com, hasanbusri@mail.unnes.ac.id, zaimelmubarok@mail.unnes.ac.id &
\end{tabular}




\section{PENDAHULUAN}

Kalimat dalam bahasa Inggris disebut sentence, kalimat juga bisa disebut dengan klausa. menurut Wojowasito sebagaimana dikutip (Kuswardono, 2019:34) adalah kesatuan bunyi tentang atau untuk pemakaian perkataanperkataan. Menurut Kridalaksana sebagaimana dikutip (Kuswardono, 2019:34) adalah satuan bahasa yang secara relatif berdiri sendiri, mempunyai pola intonasi final dan secara aktual maupun potensial terdiri dari klausa. Menurut Chaer sebagaimana dikutip (Kuswardono, 2019:34) adalah satuan sintaksis yang disusun dari konstituen dasar yang biasanya berupa klausa, dilengkapi dengan konjungsi bila diperlukan, serta disertai dengan intonasi final.

Kalimat dalam bahasa Arab disebut jumlah (جـــــ Istilah jumlah pertama kali dipakai oleh Sibawayh (w. 180 H/796 M) dalam karyanya al Kita;b. Namun konsep Sibawayh tentang jumlah berbeda dengan apa yang sekarang dipahami oleh umumnya pembelajar bahasa Arab. Sibawayh tidak konsisten dalam menggunakan istilah jumlah. Pada beberapa pernyataannya memakai kata jumlah berarti kalimat, klausa, ungkapan, dan bahasa. Istilah jumlah yang berarti klausa atau kalimat secara konsisten dikenalkan oleh ilmuan bahasa Arab bernama al Mubarrid (w. 285 H/ 898 $\mathrm{M})$, Al Lathif sebagaimana dikutip (Kuswardono, 2019:125).

Satuan gramatikal kalimat adalah konstruksi gramatikal yang tersusun dari paduan kata yang mengungkapkan sebuah gagasan atau pikiran yang utuh atau dalam bahasa Arab disebut

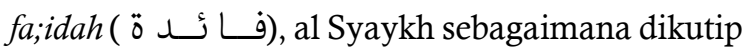
(Kuswardono, 2019:125). Menurut Hasan sebagaimana dikutip (Kuswardono, 2019:125) dalam tradisi Arab awal dikenal secara luas dua jenis kalimat utama, yaitu jumlah ismiyah (جمـلـة اسلمـيـة ) dan jumlah fi'liyah

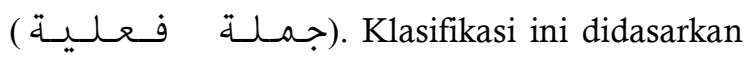
pada kategori kata dalam struktur konstituen kalimat yang mengawali kalimat tersebut. Bila kalimat diawali dengan kategori nomina dinamakan jumlah ismiyah atau kalimat nominal, sedangkan bila diawali kategori verba disebut jumlah fi'liyah atau kalimat verbal. Penelitian ini hanya akan membahas tentang jumlah ismiyah atau klausa nominal yang tersusun dari mubtada'(topic) dan khabar (comment).

Pada umumnya, terdapat beberapa fungsi sintaksis unsur-unsur kalimat, yaitu fungsi predikat, subjek, objek, pelengkap, dan keterangan, Alwi sebagaimana dikutip (Kuswardono, 2019:141).

Fungsi sintaksis Arab utama terbagi menjadi 3, yaitu musnad, musnad ilayh, dan fudhlah. Musnad dapat disepadankan dengan fungsi predikat, musnad ilayh dapat disepadankan dengan subyek, dan fudhlah dapat disepadankan dengan komplemen. Musnad dan musnad ilayh disebut 'umdah (pillar of sentence). Fungsi obyek dalam tradisi Arab masuk dalam klasifikasi komplemen. Terdapat beragam hubungan fungsional yang ditandai dengan penanda gramatikal atau desinen. Desinen tersebut menandai setiap peran semantis yang ada dalam klausa atau kalimat. Sehingga terdapat fungsi sintaksis subordinat yang melekat pada setiap peran semantis, (Kuswardono, 2019:145).

Fungsi sintaksis dalam kalimat bahasa Arab diisi oleh beberapa subfungsi atau fungsi sintaksis turunan yang dapat disepadankan dengan peran semantis. Fungsi sintaksis musnad ilayh diisi oleh peran semantis yang salah satunya yaitu mubtada' ( 1 (ــــــ fungsi sintaksis musnad diisi oleh peran semantis yang salah satunya yaitu khabar al mubtada' (خــــ), fungsi sintaksis fudhlah diisi oleh peran semantis tamyi;z (تـمـيـيـز), cha;l (حـال), al mafu;l liajlih

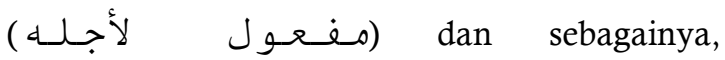
(Kuswardono, 2019:146). Penelitian ini hanya akan membahas tentang musnad berupa mubtada' (topic) dan musnad ilayh berupa khabar (comment). Adapun pembahasan khabar (comment) akan difokuskan pada khabaral mubtada'.

$$
\text { Mubtada' ( \& مــــ/ (topic) yang }
$$

ditandai sebagai kasus nominatif ( رف ع ( $)$ ) dapat disejajarkan dengan peran semantik pokok, yaitu peran yang bersangkutan dengan benda yang diterangkan oleh benda lain. Mubtada'juga dapat disepadankan dengan peran pragmatis topik, tema, dan fokus. Topik adalah pokok pembicaraan, hal yang dianggap diketahui pendengar / pembaca. Tema adalah bagian dari 
ujaran yang memberi informasi tentang apa yang diujarkan. Fokus adalah bagian ujaran yang mengandung informasi tentang aspek paling penting yang dibicarakan dalam ujaran itu sedangkan bagian-bagian lain disebut latar. (Kuswardono, 2019:150)

Khabar al mubtada' (خــــ ) / (comment) yang ditandai kasus nominatif ( disejajarkan dengan peran semantis ciri, yaitu peran yang bersangkutan dengan benda yang menerangkan benda lain. Selain itu khabar al mubtada' dapat disejajarkan dengan peran semantis atribut, yaitu peran utama predikat nominal pada kalimat yang predikatnya nomina. Khabar al mubtada' juga dapat disepadankan dengan peran pragmatis komen, rema dan latar. Komen memberikan penjelasan terhadap pokok. Komen adalah ihwal yang merupakan penjelasan tentang topik. Rema memberi informasi tentang apa yang dikatakan tentang tema. Latar adalah bagian-bagian lain yang menjelaskan informasi tentang aspek paling penting yang dibicarakan dalam ujaran. (Kuswardono, 2019:153)

Guna memperdalam pembahasan terkait dengan mubtada' (topic) dan khabar (comment), peneliti bermaksud untuk menjadikan kitab safinatun naja sebagai sumber rujukan utama. Peneliti juga memiliki tujuan untuk mendeskripsikan dan menjelaskan mubtada' (topic) dan khabar (comment) yang ada dalam kitab safinatun naja karena kitab tersebut merupakan kitab yang sering dikaji terutama dalam pesantren-pesantren di Indonesia, kitab ini membahas tentang hukum-hukum syari'at agama islam dasar yang fundamental sehingga sangat cocok dipelajari dan dikaji oleh para santri pemula, kitab ini terdapat beberapa bab dari mulai dari bab rukun islam, bab rukun iman, bab bersuci, bab solat, bab jenazah, bab zakat, dan bab puasa, oleh karenanya sudah selayaknyalah kita umat muslim mempelajari ilmu fiqih, yang salah satu pembahasannya ada pada kitab safinatun naja, peneliti juga memiliki tujuan agar pembahasan mubtada' (topic) dan khabar (comment) dalam kitab safinatun naja agar lebih mudah dipahami, diingat dan yang paling penting agar mudah diamalkan. Selain alasan diatas, penulis juga tedorong meneliti mubtada' dan khabar dalam kitab ini dikarenakan posisi mubtada' dan khabar di dalam tata bahasa yang sangat esensial bahkan ada pada disetiap bahasa, adanya predikat (mubtada') dan subjek (khabar) adalah sebuah keniscayaan, dan juga dalam kitab ini banyak diketemukan kata yang masuk dalam kategori mubtada' dan khabar.

Berdasarkan latar belakang tersebut, maka mendorong peneliti untuk melakukan penelitian dengan judul 'Mubtada' (topic) dan Khabar (comment) dalam Kitab Safinatun Naja karya Syeikh Salim Bin Abdullah Bin Said Bin Sumair Al Hadramiy (Analisis Sintaksis)"

\section{LANDASAN TEORI}

Dalam suatu penelitian, perlu adanya landasan teori yang menjadi dasar atau landasan peneliti dalam melakukan penelitian. Dalam penelitian ini, peneliti menggunakan teori yang berkenaan dengan mubtada(topic) dan khabar (comment) pada kitab safinatun naja karya Syeikh Salim bin Abdullah bin Said bin Sumair Al Hadramiy. Teori tersebut meliputi: sintaksis, kata, nomina/isim, klausa/jumlah, mubtada (topic) dan khabar (comment).

Sintaksis sering disebut sebagai tataran kebahasaan terbesar. Menurut Ramlan, sintkasis adalah bagian dari tata bahasa yang mengkaji struktur frasa dan kalimat. Hal ini selaras dengan yang dikemukakan Bloch dan Trager (dalam Tarigan) bahwa sintaksis adalah analisis mengenai konstruksi-konstruksi yang hanya mengikutsertakan bentuk-bentuk bebas. Dari berbagai pernyataan tersebut dapat dikemukakan bahwa sintaksis mengkaji hubungan antar kata dalam suatu konstruksi. Sintaksis mengkaji hubungan antara kata yang satu dengan kata yang lainnya. Dari uraian tentang tataran kebahasaan di atas dapat diketahui bahwa sintaksis merupakan cabang linguistik yang mengkaji konstruksikonstruksi yang bermodalkan kata. (Asrori, 2004:19-20).

Menurut Verhaar Sintaksis berasal dari bahasa Yunani sun dan tattein 'menempatkan'. Secara etimologis kata tersebut berarti 'menempatkan bersama-sama kata-kata menjadi kelompok kata atau kalimat'. Menurut Ramlan Kata sintaksis dalam bahasa Indonesia merupakan serapan dari bahasa Belanda syntaxis, yang dalam bahasa Inggris disebut syntax. Menurut Sugono, 
dalam kamus besar bahasa Indonesia, pengertian sintaksis adalah 1 pengaturan dan hubungan kata dengan kata atau dengan satuan lain yang lebih besar; 2 cabang linguistik tentang susunan kalimat dan bagiannya; ilmu tata kalimat. Menurut Hornby, dalam kamus bahasa Inggris, sintaksis mempunyai arti 'aturan penyusunan kalimat'. Sebaliknya menurut Umar, dalam bahasa Arab, sintaksis berarti ilmu yang membahas posisi kata dalam kalimat dan relasi antarkata dalam kalimat. (Kuswardono, 2019:3).

Menurut El Dahdah, Sintaksis dalam bahasa Arab disepadankan dengan istilah al nachw ( ) atau menurut 'Akasyah 'ilm nachw علمم atau 'ilm tandzim (علم الـنـو ) atau menurut Baalbaki juga disebut dengan 'ilm nadzm (عـمـم الـــم ) atau nadzm

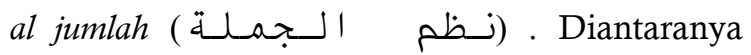
istilah tersebut yang paling banyak dipakai sebagai padanan istilah sintaksis adalah istilah al nachw ( الـنــ ), sebagaimana dikutip (Kuswardono, 2019:59)

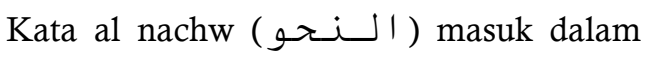
kategori nomina original atau disebut mashdar yang merupakan nomina derivatif dari dasar

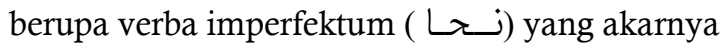

( $\left.و^{-} ح^{-} \dot{u}\right), \quad$ Ma'luf sebagaimana dikutip (Kuswardono, 2019:59). Dalam penjelasan gramatikal, kata nachw sering digunakan dalam arti: contoh atau seperti. Kedua kata tersebut adalah ekspresi untuk menyatakan sesuatu kaidah yang dituju atau dikehendaki agar maksudnya menjadi jelas dan mudah dipahami. Secara etimologi dapat dikatakan bahwa kata nachw mengandung arti contoh atau model yang dituju atau dikehendaki sesuai dengan kaidah yang menjadi acuannya, Wahab sebagaimana dikutip (Kuswardono, 2019:60).

Kajian sintaksis Arab meliputi satuan gramatikal kata sebagai bagian dari konstruksi yang lebih besar, konstruksi paduan kata, dan kalimat. Selain satuan gramatikal, sintaksis Arab juga mengkaji hubungan antar satuan sintaksis tersebut baik yang bersifat fungsional ataupun yang bersifat maknawi. Hubungan fungsional menempatkan salah satu dari dua unsur dalam kalimat sebagai musnad (مســــ) atau predikat dan unsur lainnya sebagai musnad ilayh ) atau dapat disepadankan dengan fungsi pelengkap. Hubungan maknawi selain mendeskripsikan fungsi semantik kata, frase, atau klausa dalam kalimat juga mengkaji sistem infleksi yang muncul akibat hubungan tersebut beserta desinen yang menandai kasus pada nomina atau modus pada verba yang menjadi unsur-unsur pembentuk sebuah kalimat, Kuswardono sebagaimana dikutip (Zahirotun, 2016:18).

Kata dalam sudut pandang morfologi adalah satuan terbesar yang dihasilkan dari proses morfologis. Adapun dalam sudut pandang sintaksis kata adalah satuan bahasa terkecil yang mengandung makna, Arifin sebagaimana dikutip (Kuswardono, 2019:16). Oleh sebab itu dapat dikatakan kata adalah out put terakhir dalam proses morfologis, dan menjadi input dalam proses sintakis, Kridalaksana sebagaimana dikutip (Kuswardono, 2019:16). Kata dalam bahasa Arab disebut dengan kalimah ( الـكــــ), menurut Araa'ini sebagaimana dikutip (Zahirotun 2016:19) mendefinisikan mengenai kata dalam bahasa Arab yaitu dikenal dengan istilah kalimah. Kalimah ialah sepatah kata. Kalimah terdiri atas ism (nomina), fi'il (verba) dan charf (partikel).

Menurut Al-Hasyimi sebagaimana dikutip (Zahirotun 2016:19), kata (kalimah) adalah lafaz yang mempunyai makna. Sedangkan menurut Zakaria sebagaimana dikutip (Zahirotun 2016:19) kalimah adalah lafaz yang mempunyai arti baik satu huruf, dua huruf, atau lebih. Peneliti menyimpulkan bahwa kata adalah lafaz yang menunjukkan makna/arti tanpa memperhitungkan jumlah huruf penyusunnya.

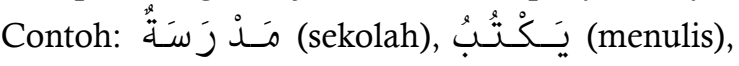
إل (ke), ل (untuk)

Satuan gramatikal kata yang menjadi unsur pengisi kalimat dapat dikelompokkan kategori sintaksisnya sesuai ciri gramatikal dan semantisnya menjadi ism (nomina), fi'il (verba), dan charf (partikel), Ghulayaini sebagaimna dikutip (Kuswardono, 2019:81). Kata pada dasarnya adalah ism (nomina), fi'il (verba), dan charf(partikel). Isim adalah kata yang menyatakan suatu benda. Fi'il adalah kata yang menyatakan gerak suatu benda. Adapaun charf adalah kata 
yang menyatakan sesuatu buka isim dan fi'il, Abanah sebagaimana dikutip (Kuswardono, 2019:81).

Nomina atau disebut isim dalam bahasa Arab adalah sesuatu yang mengandung makna dirinya sendiri tidak terkait dengan waktu, Ghulayaini sebagaimana dikutip (Zahirotun,

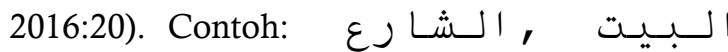

ة . Menurut Ni'mah sebagaimana dikutip (Zahirotun, 2016:20) fi'il adalah setiap kata yang menunjukkan adanya sebuah kejadian yang terjadi pada masa tertentu. Contoh : r. . charf (partikel) adalah setiap kata yang tidak mempunyai makna kecuali kata tersebut bersama kata yang lain. Contoh :

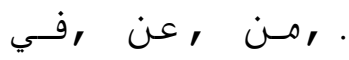

Terkait dengan infleksi, pada nomina terdapat tiga kasus, yaitu nominatif, akusatif, dan genetif atau dalam bahasa Arab disebut rafa'

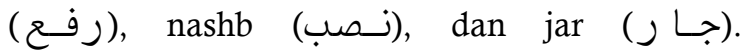
Sedangkan pada verba terdapat tiga modus, yaitu indikatif, subjungtif, dan jusif atau dalam bahasa Arab disebut rafa' (رفـع), nashb (نـصب), dan jazm (جـزمـ), Kuswardono sebagaimana dikutip (Zahirotun, 2016:24). Baik kasus nomina maupun modus verba ditandai oleh beragam penanda gramatikal atau disebut desinen yang diletakkan atau disisipkan sebagai sufiks diakhir kata. Setiap kasus menandai fungsi sintaksis tertentu pada nomina atau reksi partikel tertentu pada nomina. Sedangkan modus hanya menandai reksi partikel tertentu pada verba, Kuswardono sebagaimana dikutip (Zahirotun, 2016:24).

Perubahan bunyi akhir sebuah kata Arab dalam konstruksi yang lebih besar adalah untuk menunjukkan hubungan gramatikal atau hubungan fungsional kata tersebut dengan kata lainnya. Bunyi akhir sebuah kata Arab dalam konstruksi kalimat merupakan penanda hubungan gramatikal atau desinen. Desinen adalah afiks penanda fleksi, menurut Kridalaksana sebagaimana dikutip (Zahirotun 2016:25).

Dikarenakan penelitian ini hanya membahas nomina, maka penanda gramatikal atau desinen yang dipaparkan di sini adalah penanda kasus yang berhubungan dengan nomina yang berkasus nominatif saja. Menurut Anwar sebagaimana dikutip (Zahirotun 2016:25), penanda gramatikal (desinen) nomina dalam kasus nominatif adalah: dlammah, alif, waw dan nun. Menurut An'im (2007:74), rofa' yaitu perubahan khusus yang ditandai dengan dlammah (alamat asli) atau penggantinya (waw, alif dan nun).

Kalimat dalam bahasa Arab disebut jumlah (جــــــ Istilah jumlah pertama kali dipakai oleh Sibawayh (w. 180 H/796 M) dalam karyanya al Kita; $b$. Namun konsep Sibawayh tentang jumlah berbeda dengan apa yang sekarang dipahami oleh umumnya pembelajar bahasa Arab. Sibawayh tidak konsisten dalam menggunakan istilah jumlah. Pada beberapa pernyataannya memakai kata jumlah berarti kalimat, klausa, ungkapan, dan bahasa. Istilah jumlah yang berarti klausa atau kalimat secara konsisten dikenalkan oleh ilmuan bahasa Arab bernama al Mubarrid (w. 285 H/ 898 M), Al Lathif sebagaimana dikutip (Kuswardono, 2019:125).

Satuan gramatikal kalimat adalah konstruksi gramatikal yang tersusun dari paduan kata yang mengungkapkan sebuah gagasan atau pikiran yang utuh atau dalam bahasa Arab disebut

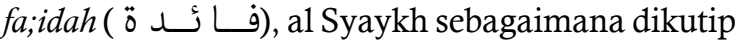
(Kuswardono, 2019:125). Menurut Hasan sebagaimana dikutip (Kuswardono, 2019:125) dalam tradisi Arab awal dikenal secara luas dua jenis kalimat utama, yaitu jumlah ismiyah

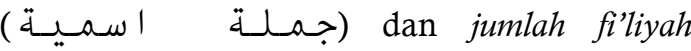

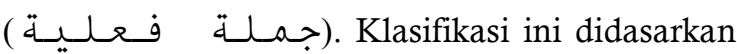
pada kategori kata dalam struktur konstituen kalimat yang mengawali kalimat tersebut. Bila kalimat diawali dengan kategori nomina dinamakan jumlah ismiyah atau kalimat nominal, sedangkan bila diawali kategori verba disebut jumlah fi'liyah atau kalimat verbal. Penelitian ini hanya akan membahas tentang jumlah ismiyah atau kalimat nominal yang tersusun dari mubtada'(topic) dan khabar (comment). Pada umumnya, terdapat beberapa fungsi sintaksis unsur-unsur kalimat, yaitu fungsi predikat, subjek, objek, pelengkap, dan keterangan, Alwi sebagaimana dikutip (Kuswardono, 2019:141).

Isim (nomina) berkasus nominatif apabila menempati 7 fungsi sintaksis, yaitu : 1) mubtada' (topic), 2) khabar (comment), 3) isim kana wa 
akhawatuha, 4) khabar inna wa akhawatuha, 5) fa'il, 6) na'ib al fa'il dan 7) at-tawabi'. Dalam penelitian ini hanya akan membahas fungsi sintaksis berupa mubtada' (topic) dan khabar (comment).

Menurut Ismail (2000:102) mubtada' (topic) adalah isim (kata benda) yang dibaca rafa' (nominatif) karena berada dipermulaan dan tidak didahului fi'il (verba) maupun charf (partikel). Menurut A. Rahman sebagaimana dikutip (Zahirotun, 2016:28) mubtada' (topic) adalah kata benda yang di rafa'kan yang dijadikan pokok kalimat (subjek) dan biasanya disebutkan di awal kalimat sehingga di rafa'kan karena jatuh sesudah kata kerja aktif (fi'il ma'lum). Sedangkan mubtada' (topic) di rafa'kan karena faktor maknawi yaitu terletak di permulaan kalimat. Sedangkan menurut (Fadilah, 2019:25) Mubtada ialah isim marfu' yang bebas dari amil lafadz yakni yang merofakan mubtada itu bukan dari amil lafadz seperti fa'il atau naibul fa'il, melainkan oleh amil maknawi, yaitu oleh ibtida atau permulaan kalimat saja. Amil yaitu lafadz maupun makna yang mempunyai amal (tugas) terhadap kalimah lain, sehingga menyebabkan suatu kalimat menjadi marfu', manshub, majrur (khusus pada isim) atau majzum (khusus pada $f i^{\prime} i$ ).

Dari beberapa pernyataan diatas, dapat diambil kesimpulan bahwa mubtada' adalah isim (nomina) yang dibaca rafa' (nominatif) yang menjadi pokok kalimat (subjek), yang bukan dari amil lafadz, melainkan oleh amil maknawi ibtida', posisinya berada dipermulaan kalimat dan tidak didahului fi'il (verba) maupun charf (partikel).

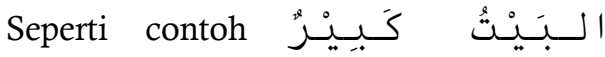
(Rumah itu besar). Lafadz $\stackrel{8}{H}^{\prime}$ menjadi mubtada' yang dirafa 'kan oleh amil maknawi ibtida' dan tanda rafa'nya dengan dhammah karena isim

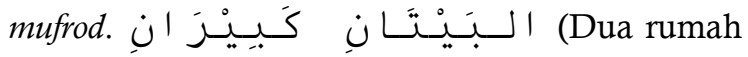

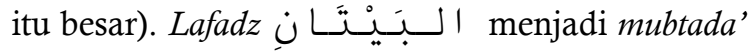
yang dirafa'kan oleh amil maknawi ibtida', dan tanda rafa'nya dengan alif karena isim tasniyah.

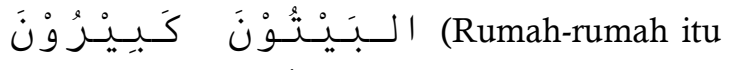

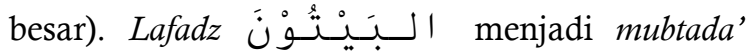
yang dirafa'kan oleh amil maknawi ibtida', dan tanda rafa'nya dengan dengan wawu karena jamak mudzakar salim.
Khabar (comment) adalah bagian yang melengkapi makna mubtada' (topic), dengan kata lain bahwa khabar (comment) merupakan bagian yang tersusun oleh jumlah mufidah guna melengkapi mubtada'(topic), Ni'mah sebagaimana dikutip (Zahirotun, 2016:34). Menurut AlGhalayaini sebagaimana dikutip (Fadilah, 2019:28) khabar merupakan isim marfu' yang musnad (disandarkan) dengan mubtada' yang menyempurnakan faidah jika bersama mubtada'. Adapun jumlah yang tersusun dari mubtada' dan khabar disebut jumlah ismiyyah. Menurut (Hakim, 2003:27) khabar adalah bagian dari kalimat yang menyempurnakan faedah dari jumlah ismiyyah (mubtada' dan khabar), sehingga kalimat tersebut bisa dipahami. Sedangkan menurut Zahirotun (2016:34) Khabar (comment) atau komentar adalah pasangan dari mubtada' (topic) yang memberikan makna secara utuh dalam kalimat, atau dengan kata lain khabar (comment) adalah hal yang berkenaan dengan mubtada' (topic) sehingga tanpa ada khabar (comment), sebuah kalimat tidak bisa dipahami. Kombinasi antara makna dari khabar (comment) dan makna dari mubtada'(topic) inilah yang menghasilkan makna yang diharapkan dari sebuah klausa nominal ( جـمـلـة الســـــ).

Dari beberapa pernyataan diatas, dapat diambil kesimpulan bahwa khabar (comment) adalah isim (nomina) yang dibaca rafa'(nominatif) guna melengkapi makna mubtada'(topic) sehingga memberikan makna secara utuh dalam kalimat.

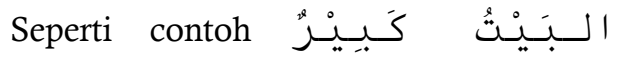

(Rumah itu besar). Lafadz كَـ menjadi khabar yang dirafa 'kan oleh mubtada' dan tanda rafa'nya dengan dhammah karena isim mufrod. (Dua rumah itu

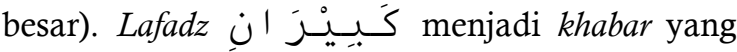
dirafa'kan oleh mubtada', dan tanda rafa'nya

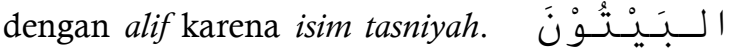
كَـــــ (Rumah-rumah itu besar). Lafadz

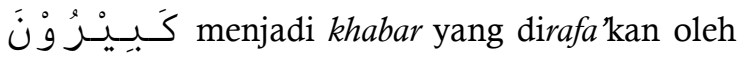
mubtada', dan tanda rafa'nya dengan dengan wawu karena jamak mudzakar salim. Contoh diatas tergolong klausa nominal, yang mana susunan kalimat seperti ini bertujuan untuk menyampaikan

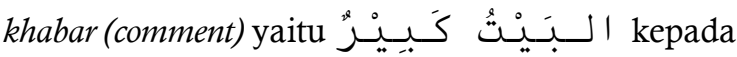
pembaca dan pendengar. 


\section{METODE PENELITIAN}

Penelitian tentang mubtada' (topic) dan khabar (comment) dalam kitab safinatun naja karya Syeikh Salim bin Abdullah bin Said bin Sumair al Hadramiy merupakan jenis penelitian deskriptif kualitatif, serta menggunakan desain penelitian studi pustaka. Menurut Strauss dan Corbin sebagaimana dikutip (Nugraheni, 2014:9) Penelitian kualitatif merupakan penelitian yang jenis temuannya tidak didapat melalui prosedur penelitian statistik atau dalam bentuk hitungan lainnya. Menurut Ibnu sebagaimana dikutip (Ainin, 2010:12) penelitian kualitatif adalah suatu penelitian yang datanya dinyatakan dalam bentuk verbal dan dianalisis tanpa menggunakan teknik statistik. Menurut Creswell sebagaimana dikutip (Raco, 2010:7) mendefinisikan tentang metode penelitian kualitatif "sebagai suatu pendekatan atau penelusuran untuk mengeksplorasi dan memahami gejala sentral". Penelitian yang dilakukan oleh peneliti jenis temuannya tidak dalam bentuk hitungan, namun jenis temuannya adalah berupa penelitian ilmiah mubtada' (topic) dan khabar (comment) dalam kitab safinatun naja karya Syeikh Salim bin Abdullah bin Said bin Sumair al Hadramiy.

Dalam penelitian ini peneliti menggunakan desain penelitian library research atau yang sering disebut dengan penelitian pustaka. Karena data yang diperoleh berbentuk dokumen yang berasal dari sebuah buku. Seperti yang telah dikemukakan oleh Zed sebagaimana dikutip (Zahirotun, 2016:45) bahwa penelitian kepustakaan merupakan serangkaian kegiatan yang berkenaaan dengan metode pengumpulan data pustaka, membaca, dan mencatat serta mengolah bahan penelitian. Dengan riset pustaka, peneliti memanfaatkan sumber perpustakaan untuk memperoleh data penelitian, dan membatasi kegiatan hanya pada bahanbahan koleksi perpustakaan saja tanpa memerlukan riset lapangan.

Data terbentuk dari beberapa karakter yang dapat berupa angka, simbol, alfabet dan merupakan bentuk yang masih mentah, sehingga perlu diolah lebih lanjut melalui model-model tertentu sehingga menghasilkan sebuah informasi (Edi, Doro; Betshani, Stevalin., 2009:72). Didalam penelitian ini data yang teliti adalah berupa mubtada'(topic) dan khabar (comment) dalam kitab safinatun naja karya Syeikh Salim bin Abdullah bin Said bin Sumair al Hadramiy yang teliti melalui sumber-sumber data terpercaya seperti buku, jurnal dan lain sebagainya sehingga mendapatkan informasi yang akurat. Menurut (Mursyid, 2016:23) data primer ialah data yang dikumpulkan peneliti secara langsung dari sebuah sumber data. Sedangkan data sekunder ialah data yang dikumpulkan peneliti dari berbagai sumber yang ada. Sumber data yang digunakan peneliti disini hanya berupa sumber data primer berupa kitab mubtada' (topic) dan khabar (comment) dalam kitab safinatun naja karya Syeikh Salim bin Abdullah bin Said bin Sumair al Hadramiy yang terdiri dari $74 \mathrm{bab}$, mulai bab rukun islam sampai bab tentang hal-hal yang membatalkan puasa.

Objek yang digunakan dalam penelitian ini adalah mubtada(topic) dan khabar (comment) pada teks di dalam kitab safinatun naja karya Syeikh Salim bin Abdullah bin Said bin Sumair Al Hadramiy. Menurut Sugiono sebagaimana dikutip (Zahirotun, 2016:47) menyatakan bahwa, definisi objek penelitian adalah sebagai berikut: "Objek penelitian merupakan suatu atribut atau sifat atau nilai dari orang, objek atau kegiatan yang mempunyai variasi tertentu yang ditetapkan oleh peneliti untuk di pelajari dan kemudian ditarik kesimpulannya."

Dilihat dari fungsi dan kedudukannya, objek penelitian dibedakan menjadi dua macam, yaitu obyek formal dan obyek material. Adapun obyek formal adalah obyek yang dianalisis, dalam penelitian ini yaitu data yang berkaitan dengan mubtada'(topic) dan khabar (comment) dan objek material dalam penelitian ini yaitu teks bacaan di dalam kitab safinatun naja karya Syeikh Salim bin Abdullah bin Said bin Sumair Al Hadramiy.

Dalam peneitian ini, peneliti mengumpulkan data-data berupa mubtada(topic) dan khabar (comment) pada kitab safinatun naja karya Syeikh Salim bin Abdullah bin Said bin Sumair Al Hadramiy, setelah data-data yang diperlukan terkumpul akan dilakukan abstraksi atau pemberian gambaran pada sebuah data sebelum nanti peneliti memberikan pandangan atau pendapat pada sebuah data dan menyimpulkan semua data-data yang diperoleh dalam penelitian. 
Dalam penelitian ini terdapat 279 data berupa mubtada(topic) dan khabar (comment) pada kitab safinatun naja karya Syeikh Salim bin Abdullah bin Said bin Sumair Al Hadramiy. Kemudian dengan menggunakan teknik sampel pertimbangan (purposive sampling), peneliti mengambil sejumlah 89 data sebagai sampel yang mempresentasikan populasi data yang ada.

Instrumen dalam penelitian ini adalah dengan menggunakan kartu data dan lembar rekapitulasi yang mengandung mubtada(topic) dan khabar (comment) pada kitab safinatun naja karya Syeikh Salim bin Abdullah bin Said bin Sumair Al Hadramiy. Instrumen ini sebagai alat bantu yang secara teknis dapat menjadi salah satu cara untuk mengumpulkan dan mengolah data kemudian menganalisisnya.

Dalam penelitian ini peneliti menggunakan uji kredibilitas untuk pemeriksaan keabsahan data. Uji kredibilitas ini dilakukan dengan meningkatkan ketekunan dalam bentuk pengecekan kembali apakah data yang telah ditemukan itu benar atau tidak, dengan cara melakukan pengamatan secara berkesinambungan dan membaca berbagai referensi buku maupun hasil penelitian. Dengan meningkatkan ketekunan tersebut, peneliti akan melakukan pemeriksaan data secara berkesinambungan agar dapat mendeskripsikan data dengan akurat dan sistematis.

peneliti menganalisis data dengan tata cara sebagai berikut:

1. Mengidentifikasi kata yang terdapat pada kitab safinatun naja karya Syeikh Salim bin Abdullah bin Said bin Sumair Al Hadramiy.

2. Memilih kata yang mengandung mubtada(topic) dan khabar (comment) pada kitab safinatun naja karya Syeikh Salim bin Abdullah bin Said bin Sumair Al Hadramiy.

3. Mencatat kata yang telah dipilih pada kartu data.

4. Menganalisis data yang ada pada kartu data secara cermat dan sistematis.

5. Menyimpulkan hasil penelitian.

\section{HASIL DAN PEMBAHASAN}

Penelitian ini merupakan studi analisis mubtada' (topic) dan khabar (comment) yang terdapat dalam kitab safinatun naja karya Syeikh Salim bin Abdullah bin Said bin Sumair Al Hadramiy dengan jenis penelitian kualitatif dan desain penelitian kepustakaan (library research). Berdasarkan hasil penelitian, peneliti menyimpulkan bahwa: (1) Peneliti menemukan 89 mubtada' (topic) dan 89 khabar (comment) yang terdapat dalam kitab safinatun naja; (2) Dari 89 mubtada' (topic), 89 merupakan mubtada' (topic) sharih yang terdiri dari 80 isim zhahir dan 9 isim dlamir, 46 isim mudzakkar dan 43 isim muannats, dan 57 isim mufrad, tidak ada satupun isim tatsniah, dan 32 isim jama' dan tidak ada satupun mubtada' (topic) muawwal, sedangkan berdasarkan ketentuan penggunaan mubtada' (topic) terdiri atas tidak ada satupun mubtada' (topic) yang wajib mahdzuf atau dibuang dan 3 boleh mahdzuf atau dibuang, 82 wajib muqaddam atau diawalkan dan 2 boleh muqaddam atau diawalkan, dan 1 wajib muakhkhar atau diakhirkan dan 1 boleh muakhkhar atau diakhirkan. Dan dari 89 khabar (comment), 64 merupakan khabar (comment) mufrad yang terdiri dari 58 isim mufrad, 6 isim tatsniah dan tidak ada satupun isim jama', 34 isim mudzakkar, 30 isim muannats dan 25 khabar (comment) ghairu mufrad yang terdiri dari 7 jumlah fi'liyyah, tidak ada satupun jumlah ismiyyah dan 18 syibhul jumlah. Sedangkan berdasarkan ketentuan penggunaan khabar (comment) terdiri atas tidak ada satupun khabar (comment) yang wajib dan boleh mahdzuf atau dibuang, 1 wajib dan boleh muqaddam atau diawalkan, dan 85 wajib muakhkhar atau diakhirkan dan 2 boleh muakhkhar atau diakhirkan; (3) penanda gramatikal pada mubtada' (topic) dalam kitab safinatun naja terdiri atas 75 mubtada' (topic) dengan penanda gramatikal dlammah, tidak ada satupun mubtada' (topic) dengan penanda gramatikal alif, tidak ada satupun mubtada' (topic) dengan penanda gramatikal waw, tidak ada satupun mubtada' (topic) dengan penanda gramatikal nun, dan 14 mubtada' (topic) dengan kasus nominatif yang menempati fungsi mubtada' (topic) (machal rafa'). Sedangkan penanda gramatikal pada khabar (comment) dalam kitab safinatun naja terdiri atas 57 mubtada' (topic) dengan penanda gramatikal dlammah, 6 mubtada' (topic) dengan penanda gramatikal alif, tidak ada satupun mubtada' (topic) dengan penanda gramatikal waw, tidak ada satupun mubtada' (topic) dengan penanda gramatikal nun, dan 26 mubtada' (topic) dengan kasus nominatif yang menempati fungsi mubtada' (topic) (machal rafa'). 


\section{DAFTAR PUSTAKA}

Agusta, I. (2003, Februari Kamis). Teknik Pengumpulan dan Analisis Data Kualitatif.

Ainin, M. (2010). Metodologi Penelitian Bahasa Arab. Surabaya: Hilal Pustaka.

An'im, A. (2007). Sang Pangeran Nahwu Al Ajurumiyyah. Kediri: Mu'jizat Group.

Arikunto, S. (2010). Prosedur Penelitian Suatu Pendekatan Praktik. Jakarta: PT Rineka Cipta.

Asrori, I. (2004). Sintaksis Bahasa Arab. Malang: Misykat.

Edi, Doro; Betshani, Stevalin. (2009). Analisis Data dengan menggunakan ERD dan Model Konseptual Warehouse. Jurnal Informatika, $\mathrm{V}$.

Effendy, A. F. (2017). Metodologi Pengajaran Bahasa Arab. Malang: Penerbit Misykat.

Fadilah, A. N. (2019). Mubtada (Topic) berupa Isim Nakirah (Nomina Indefinit) dalam buku Fath al-Qarib al-Mujib.

Hakim, T. (2003). Qosidati Program Pemula Membaca Kitab Kuning. Jepara: Al-Falah Offset.

Ismail, M. B. (2000). Qawa'id An Nahwi Bi Uslub Al Ashri. Mesir: Dar Al Manar.

Kuswardono, S. (2013). Sosiolinguistik Arab. Makasar: Dapur Buku.

Kuswardono, S. (2019). Tradisi Nahwu Dalam Tinjauan Linguistik Pengantar Sintaksis Arab. Banyumas: Rizquna.
Mekarisce, A. A. (2020). Teknik Pemeriksaan Keabsahan Data pada Penelitian Kualitatif di Bidang Kesehatan Masyarakat. Jurnal Ilmiah Kesehatan Masyarakat, 12 Edisi 3.

Mursyid, A. (2016). Panduan Penulisan Tugas Akhir Skripsi. Yogyakarta: Politeknik Kesehatan Kemenkes.

Nisa, A. (2017). Tarkib Idhafiy Dalam Buku Ta'limu Al Lughatu Al 'Arabiyyah Li Ghairi Al Arab (Analisis Sintaksis).

Nisak, A. (2017). Huruf Athaf Dalam Surat AlIsra' (Analisis Sintaksis).

Nugraheni, F. (2014). Metode Penelitian Kualitatif. Surakarta: Cakra Books.

Raco, J. (2010). Metode Penelitian Kualitatif Jenis, Karakteristik, dan Keunggulannya. Jakarta: PT Gramedia Widiasarana Indonesia.

Susilana, R. (2015). Modul 6 Populasi dan Sampel. Universitas Pendidikan Indonesia.

Zahirotun, N. (2016). Mubtada' Dan Khabar Pada Teks Bacaan Shalat Dalam Buku Risalah Tuntunan Shalat Lengkap Karya Drs Muhammad Rifa'i dan Juz 30 Sebagai Bacaan Surat Pilihan (Analisis Sintaksis).

Zahroh, L. (2017). Ism al-Ma'rifah (Nomina Definit) dalam buku Ta'lim al-Lughah alArabiyyah Lighair al-Arab (Analisis Sintaksis). Universitas Negeri Semarang. 